\title{
Sensitivity of Erysiphe necator and Plasmopara viticola in Virginia to Qol Fungicides, Boscalid, Quinoxyfen, Thiophanate Methyl, and Mefenoxam
}

Jeneylyne F. Colcol, Monsanto Company, Huxley, IA 50124; and Anton B. Baudoin, Department of Plant Pathology, Physiology and Weed Science, Virginia Tech, Blacksburg 24061

\begin{abstract}
Colcol, J. F., and Baudoin, A. B. 2016. Sensitivity of Erysiphe necator and Plasmopara viticola in Virginia to QoI fungicides, boscalid, quinoxyfen, thiophanate methyl, and mefenoxam. Plant Dis. 100:337-344.

The sensitivity of downy mildew (DM, Plasmopara viticola) and powdery mildew (PM, Erysiphe necator) of grape (Vitis sp.) to commonly used nondemethylation inhibitor, single-site fungicides in and near Virginia was determined from 2005 to 2007 , with more limited additional sampling in subsequent years. In grape leaf disc bioassays, $92 \%$ of the $P$. viticola isolates were quinone outside inhibitor (QoI, azoxystrobin) resistant but none were resistant to mefenoxam. In all, $82 \%$ of the E. necator isolates were QoI resistant. Most of the QoI-resistant $P$. viticola and $E$. necator isolates contained $>95 \%$ of the G143A point mutation, which confers high levels of QoI resistance. In contrast, QoI-sensitive $P$. viticola isolates contained less than 1\% of G143A. In total, 1 of 145 and 14 of 154 QoI-resistant $P$. viticola and $E$. necator isolates (able to grow on azoxystrobin concentration

$\geq 1 \mu \mathrm{g} / \mathrm{ml}$ ), respectively, contained $<1 \%$ G143A. In total, 61 E. necator isolates from 23 locations were tested against thiophanate methyl, and the majority grew well on leaf tissue treated with 50 and $250 \mu \mathrm{g} / \mathrm{ml}$. Through 2012, none of the E. necator isolates were resistant to boscalid and quinoxyfen. However, in 2013, quinoxyfen-resistant E. necator was detected in one vineyard experiencing difficulties with powdery mildew control. No 50\% effective concentration value could be calculated but these isolates tolerated labeled rates with only limited inhibition. QoI (E. necator and $P$. viticola) and benzimidazole (E. necator) resistance were widespread in Virginia, rendering these materials inadvisable for control of these diseases. The practical importance and current distribution of quinoxyfen resistance needs further investigation.
\end{abstract}

Powdery mildew (Erysiphe [Uncinula] necator Schwein.] and downy mildew (Plasmopara viticola (Berk. \& M. A. Curtis) Berl. \& De Toni) are among the most important grape (Vitis spp.) diseases worldwide and frequently damage grapevines in eastern North America (Wong and Wilcox 2000, 2002). Because a majority of valuable grape cultivars are moderately to highly susceptible to these diseases, they have generally been managed with intensive fungicide applications. The older chemicals, such as sulfur, copper, captan, and mancozeb, are considered to have multisite modes of action but fungicide groups introduced since the 1960s almost all have a singlesite mode of action and, with these groups, resistance development by the pathogen can turn into a serious problem (Brent and Hollomon 2007). Previously, we reported on the presence of quinone outside Inhibitor (QoI) resistance in both E. necator (Baudoin et al. 2008; Colcol 2008) and P. viticola (Baudoin et al. 2008), and on tolerance of E. necator to demethylation inhibitor (DMI) fungicides (Colcol 2008; Colcol et al. 2012) in Virginia and nearby states. Here, we expand on the QoI findings and report on the sensitivity status of these pathogens to other groups of fungicides at risk of resistance development. Portions of this report were part of a thesis by the first author (Colcol 2008).

The benzimidazoles were the first major group of grape fungicides against which a serious resistance problem developed. This group is active against powdery mildew, black rot, Botrytis bunch rot, and several other grape diseases but not against downy mildew. Benomyl has been used on grape cultivars in the United States since the early 1970s but, until 1994 (Ypema et al. 1997), powdery mildew was listed on the label only for "East of the Rockies"; use in western regions was labeled only against other diseases such as Botrytis bunch rot. Benomyl resistance of grape powdery mildew was documented in New York (Pearson and Taschenberg 1980) but was uncommon in California in 1993 to 1995 (Ypema et al. 1997). Benomyl was withdrawn in 2001, and

Corresponding author: A. Baudoin; E-mail: abaudoin@vt.edu

Accepted for publication 13 May 2015.

http://dx.doi.org/10.1094/PDIS-01-15-0012-RE

(C) 2016 The American Phytopathological Society thiophanate methyl received a grape tolerance in 2002 for control of the same diseases. We believe that it has received only limited use on grapevines in Virginia. We have been unable to find documentation of benzimidazole resistance in Virginia grape powdery mildew although it is considered likely to be present.

Metalaxyl (a mixture of two stereoisomers) and mefenoxam (the active stereoisomer) belong to the class phenylamides (Gisi and Cohen 1996; Gisi and Sierotzki 2008a) and have been available in the U.S. grape market since 1993. They are effective against plantpathogenic oomycetes such as $P$. viticola but not against true fungi such as the powdery mildews. They inhibit the ribosomal RNA polymerase of the target pathogen, and are categorized by the Fungicide Resistance Action Committee (FRAC) (FRAC 2015) as at high risk of resistance development. Commercial use of metalaxyl started in Europe in 1977, and metalaxyl-resistant $P$. viticola isolates were detected as early as 1983 in France (Gisi and Cohen 1996; Leroux and Clerjeau 1985) and, more recently, in 2005 in Australia (Wicks et al. 2005). To date, there is no report of mefenoxam-resistant $P$. viticola isolates on grapevines in the United States. The mechanism conferring resistance to mefenoxam has not been elucidated but may involve a major gene and several minor genes (Blum and Gisi 2008; Gisi and Sierotzki 2008a).

The QoI fungicides have been particularly attractive to grape growers because several are effective in the control of a broad spectrum of the major foliar and fruit diseases, including powdery mildew and downy mildew, as well as black rot (Wong and Wilcox 2002). The first agricultural QoI fungicide became commercially available in 1996 (Bartlett et al. 2002; Gisi et al. 2002; Ma and Michailides 2005). Azoxystrobin was introduced to the U.S. grape market in 1997, followed by kresoxim-methyl in 2000, trifloxystrobin in 2001, and pyraclostrobin in 2003. Famoxadone and fenamidone, which have the QoI mode of action but do not belong to the strobilurin subgroup and which have activity only against grape downy mildew, were registered in 2008 (as a mixture with cymoxanil) and 2009, respectively, for use on U.S. grape cultivars.

Not long after the introduction of QoI, several QoI-resistant plant pathogens were detected in a number of crops in different countries (Bartlett et al. 2002; Gisi et al. 2000, 2002) which included E. necator (Baudoin et al. 2008; Miles et al. 2012; Wilcox et al. 2003) and 
P. viticola (Baudoin et al. 2008; Colcol 2008; Gisi et al. 2002; Sierotzki et al. 2005; Toffolatti et al. 2007). However, other pathogens remained sensitive such as Sclerotinia sclerotiorum in oilseed rape, Phytophthora infestans in potato, Puccinia triticina in wheat, and Phakopsora pachyrhizi in soybean (FRAC 2012). An updated list of plant pathogens that developed resistance to fungicides can be accessed at the FRAC website (www.frac.info).

The target of the QoI is the Qo site of the cytochrome (cyt) bcl enzyme complex (Genet et al. 2006; Gisi et al. 2002). Mutations in two "hot-spot" regions of the $c y t b$ gene have been discovered as causes of resistance (Chen et al. 2007; Gisi et al. 2000; Gisi and Sierotzki 2008a,b; Ma and Michailides 2005; Sierotzki et al. 2005). Three point mutations that cause single-amino-acid changes in the enzyme complex have been responsible for most occurrences of resistance in the field: G143A, which changes glycine to alanine; F129 L, which changes phenylalanine to leucine; and G137R, which changes glycine to arginine (Sierotzki et al. 2007). G143A is the major mutation because it causes a higher level of resistance than F129 L and G137R (Gisi et al. 2000, 2002; Gisi and Sierotzki 2008a; Ma and Michailides 2005; Sierotzki et al. 2005, 2007). The G143A amino acid change is the cause of fungicide resistance in several pathogens, including $P$. viticola, Blumeria graminis $\mathrm{f}$. sp. tritici, Pseudoperonospora cubensis, Mycosphaerella fijiensis, Sphaerotheca fuliginea, Pyricularia grisea, and Didymella bryoniae (Bartlett et al. 2002; Sirven and Beffa 2003). The F129L mutation confers a lower resistance level than G143A, often occurs at lower frequencies in a sample when present with G143A (Sierotzki et al. 2005), and may reduce fitness (Toffolatti et al. 2007). This second mutation was detected in P. grisea and Pythium aphanidermatum on turf (Bartlett et al. 2002; Grasso et al. 2006; Kim et al. 2003), Alternaria solani, and Plasmopara viticola (Sierotzki et al. 2005). Additional mechanisms of resistance have been described, such as the activation of an alternative oxidase in M. graminicola that causes it to be less sensitive to QoI fungicides (Ma and Michailides 2005).

Boscalid and quinoxyfen have both been available in the United States to control grape powdery mildew (but not downy mildew) since 2003. Boscalid has a broad spectrum of activity (Avenot et al. 2008) and targets the enzyme succinate dehydrogenase (SDH) in the mitochondrial electron transport chain (FRAC 2015; Stammler et al. 2007). Resistance to boscalid has been detected in A. alternata (Avenot et al. 2008), Botrytis cinerea (FRAC 2015), D. bryoniae (Avenot et al. 2012), Corynespora cassiicola (Miyamoto et al. 2009), and Podosphaera xanthii (McGrath and Miazzi 2008; Miyamoto et al. 2010). Several fungal species in the field, as well as laboratory mutants, have been known to contain target site mutations in the SDH gene conferring high levels of resistance (FRAC 2015). FRAC currently characterizes the risk of resistance development as medium to high for this group.

Quinoxyfen belongs to the group of azanapthalenes or quinolines and its mode of action is still not completely understood (FRAC 2015; Hollomon et al. 1997). Effects on G proteins in early cell signaling and inhibition of serine esterase have been reported (Lee et al. 2008; Wheeler et al. 2003). Quinoxyfen controls Blumeria graminis f. sp. hordei (powdery mildew of grasses such as barley) by interfering with germination and formation of appressoria (Lee et al. 2008; Wheeler et al. 2003). Quinoxyfen is categorized by FRAC as at medium risk of resistance development (FRAC 2015). Quinoxyfenresistant $B$. graminis f. sp. hordei samples have been generated in the laboratory when quinoxyfen-sensitive $B$. graminis f. sp. hordei were exposed to $N$-nitrosoguanidine, which is a chemical mutagen (Hollomon et al. 1997), and have also been obtained in the field (FRAC 2014). These quinoxyfen-resistant isolates were defective and could survive in culture only in the presence of quinoxyfen (Hollomon et al. 1997; Wheeler et al. 2003). Quinoxyfen-"adapted" isolates of E. necator, "able to grow actively at a discriminatory dose of either proquinazid or quinoxyfen which controls baseline isolates", have been observed in the field in Europe (FRAC 2014; Genet and Jaworska 2009; Green and Duriatti 2005; Green and Gustafson 2006) but no published data on their practical significance appear to be available.

\section{Materials and Methods}

General. The locations and methods for the collection, maintenance, and bioassay of the E. necator isolates were as described previously (Colcol 2008; Colcol et al. 2012). Single-conidial-chain $E$. necator isolates were maintained on immature grape leaves in water agar plates. They were tested against azoxystrobin, boscalid, quinoxyfen, and benzimidazoles. Bioassays were done with at least six leaf discs per treatment, which were inoculated in a settling tower (Reifschneider and Boiteux 1988) to ensure uniform deposit of spores on the leaf discs. The majority of benzimidazole bioassays were done by inoculating fungicide-treated leaf discs with small clumps of conidia and determining colony diameters, or evaluating the presence or absence of growth and sporulation.

The leaves used for the maintenance and bioassay of the Plasmopara viticola isolates were the youngest fully expanded leaves, which had just lost their shine (leaf position 4 to 6 from the tip; Wong and Wilcox 2000), from actively growing, greenhouse-grown Chardonnay grape shoots. They were surface disinfested in $10 \%$ bleach with $0.1 \%$ Tween 20 for $2 \mathrm{~min}$ with regular agitation, rinsed three times in sterile distilled water, and blotted dry between paper towels.

$P$. viticola isolates were obtained from infected grape leaves collected from Virginia, Maryland, North Carolina, and Pennsylvania vineyards between 2005 and 2007 by researchers or grape growers; they were from the same regions and often the same vineyards illustrated previously (Baudoin et al. 2008; Colcol et al. 2012). P. viticolainfected leaf samples were placed in Ziploc bags, which were either mailed if collected by the growers, or placed in a cooler and transported immediately to the laboratory if collected by the researchers. Leaves were examined microscopically for the presence of sporulating $P$. viticola. Sporangiophores of $P$. viticola were picked from grape leaf samples using sterile, fine-tipped tweezers (number 5-A), placed into a drop of water on the abaxial surface of grape leaves, and incubated overnight in darkness at room temperature to allow infection. The following morning, the drops of water were removed by holding the plates upside down and flicking off the water droplets and the leaves were allowed to dry in the laminar-flow hood. The plates were incubated at room temperature under a 12-h photoperiod, as described for E. necator (Colcol et al. 2012).

After incubation, the grape leaves were observed under a dissecting microscope at $\times 40$ magnification to check for $P$. viticola growth and sporulation. Individual single-sporangiophore $P$. viticola isolates were obtained from the initial transfers by picking a single sporangiophore with tweezers and transferring it to a new leaf, as described above. The single-sporangiophore isolation was repeated three consecutive times to ensure the purity of each isolate. Inoculated leaves were incubated as described above. Isolates were transferred every 10 to 14 days or as frequently as necessary. For longer storage, sporulating isolates on grape leaf strips were placed in 2-ml cryotubes and allowed to dry overnight in the laminar-flow hood with the fan running, and the tubes were stored in a freezer at $-80^{\circ} \mathrm{C}$.

Biological assay. Sources of technical-grade fungicides used were: azoxystrobin and mefenoxam, Syngenta Crop Protection, Inc.; boscalid, BASF Corporation; and quinoxyfen (technical, as well as formulated Quintec), Dow AgroSciences LLC. Thiophanate methyl was used as formulated Topsin M 70\% wettable powder (United Phosphorus, Inc.). Stock solutions in acetone (final acetone concentration below $0.5 \%$ ) and aqueous serial dilutions from technical material were prepared as described previously (Colcol et al. 2012), whereas formulated products were prepared as aqueous suspensions.

E. necator isolates were tested against azoxystrobin, boscalid, and quinoxyfen at concentrations that depended on preliminary results. A sensitive subgroup from locations not exposed to commercial spray programs, which did not grow with azoxystrobin, boscalid, and quinoxyfen at $0.3 \mu \mathrm{g} / \mathrm{ml}$, was tested again at lower concentrations of $0.001,0.007,0.04$, and $0.15 \mu \mathrm{g} / \mathrm{ml}$ to determine their median $50 \%$ effective concentration $\left(\mathrm{EC}_{50}\right)$ value and the repeatability of the bioassays. This sensitive subgroup was the same as was used previously (Colcol et al. 2012) as the basis of comparison for DMI fungicide sensitivity. 
$P$. viticola isolates were tested against azoxystrobin at 1,10 , and $20 \mu \mathrm{g} / \mathrm{ml}$ and mefenoxam at 1 and $10 \mu \mathrm{g} / \mathrm{ml}$. Leaf discs were prepared for $P$. viticola bioassay as described previously (Colcol et al. 2012) for E. necator, except that more mature leaves, as described above, were used. Leaf discs for $P$. viticola assays were placed in the petri dish with the abaxial surface exposed. The majority of the isolates were assayed at least twice.

When the leaf discs were soaked in azoxystrobin at a concentration above $10 \mu \mathrm{g} / \mathrm{ml}$ (and, to a lesser extent, at lower concentrations), the edges, and often the entire disc, would turn necrotic within $24 \mathrm{~h}$. To get around this problem, we sprayed leaves that were still attached to the plant with formulated azoxystrobin (Abound) at 10 and $30 \mu \mathrm{g}$ active ingredient (a.i.)/ml, allowed them to dry at greenhouse temperature, and collected the leaves and placed them in separate Ziploc bags. The leaves were not disinfested but were cut into discs and placed into water agar plates. Leaves not treated with fungicide were used as control.

$P$. viticola spore suspensions were prepared by shaking a grape leaf piece infected with 7- to 10-day-old culture in a tube with sterile distilled water. The concentration of the spore suspension was determined using a hemacytometer and diluted to a minimum of $2 \times$ $10^{4} / \mathrm{ml}$. Using a sterile Pasteur pipette, approximately $10 \mu \mathrm{l}$ of the spore suspension was placed on the center of each leaf disc. The inoculated discs were kept in the dark overnight; then, the inoculum drops were removed and the discs were incubated as described above for culture maintenance.

After 7 to 8 days of incubation, each leaf disc was evaluated for the presence or absence and severity of disease and of sporulation. The following rating scale was used to score each leaf disc with the aid of a dissecting microscope at $\times 40$ magnification: $0=$ no disease, no growth of $P$. viticola; $1=1$ to $20 \%$ of the disc's leaf area has growth with no or very little sporulation; $2=21$ to $40 \%$ of the disc's leaf area has growth with limited sporulation; $3=41$ to $60 \%$ of the disc's leaf area has growth with moderate sporulation; $4=61$ to $80 \%$ of the disc's leaf area has growth with abundant sporulation; and $5=81$ to $100 \%$ of the disc's leaf area has growth with very abundant sporulation.

The statistical analyses for both $E$. necator and P. viticola bioassays were as described previously (Colcol et al. 2012).

According to Green and Gustafson (2006), the leaf disc bioassay can effectively and accurately detect quinoxyfen-sensitive $E$. necator isolates but may overestimate the frequency of E. necator isolates with reduced sensitivity to quinoxyfen; therefore, we also used their more quantitative germination/germ tube elongation inhibition assay. Fungicide suspensions were prepared from formulated Quintec provided by the manufacturer. Dilutions of $100,33,11$, and 3.6 or, in one experiment, $50,15,5$, and $1.5 \mu \mathrm{g}$ a.i./ml were prepared and grape leaf pieces of approximately $2 \mathrm{~cm}^{2}$ were soaked for $1 \mathrm{~h}$. Half were then blotted on clean paper towels and placed on water agar, and the other half were placed adaxial side down on Whatman number 1 filter paper drenched with the same Quintec suspension, incubated for another $24 \mathrm{~h}$ (as described by Green and Gustafson 2006), and then blotted and placed on water agar. The leaf pieces were inoculated in the settling tower. After 2 days, nail polish (Sally Hansen "Dries Instantly" Top Coat, www.sallyhansen.com) was brushed onto some of the leaf pieces and allowed to dry, and the nail polish layer was removed and mounted in lactoglycerin (1:1:1 glycerol, lactic acid, and water) with $0.1 \%$ aniline blue. Germinated and nongerminated spores were counted at $\times 100$ magnification, and germ tube lengths were measured with an ocular micrometer. At 6 and 10 days after inoculation, colonies per leaf piece (recognizable as sporulating colony centers) were counted. In one experiment, leaf pieces were placed in a vial 10 days after inoculation, and $1 \mathrm{ml}$ of $30 \%$ ethanol was added. Conidial concentrations were determined by counting conidia in two separate drops using a hemacytometer.

Molecular assay. The methods described by Sirven and Beffa (2003) and Baudoin et al. (2008) were adapted and modified to detect the presence of the G143A mutation in the $c y t b$ gene.

The DNA that was used as template for the real-time polymerase chain reaction (PCR) was extracted from spore suspensions of
$E$. necator and $P$. viticola. The $P$. viticola spore suspension was prepared by putting leaf pieces with abundant sporulation of $P$. viticola in a 10-ml tube with $2 \mathrm{ml}$ of sterile distilled water. Using a Pasteur pipette, water was flushed onto the leaf to wash off the spores. This was done repeatedly until most of the spores on the leaf were collected. The spore suspension was thoroughly mixed using a Vortex Jr. Mixer (Scientific Industries Inc.) and the leaf pieces removed from the tube. The concentration of the spores in the suspension was determined using a hemacytometer and was adjusted to between 2 and $4 \times 10^{4} / \mathrm{ml}$. Spore suspensions were transferred to $2-\mathrm{ml}$ microcentrifuge tubes, which were either stored at $-80^{\circ} \mathrm{C}$ or immediately used for DNA extraction. Spore suspensions were centrifuged at $9,300 \times g$ for $10 \mathrm{~min}$, after which the supernatant was discarded to obtain the spore pellet. E. necator spores were collected by scraping conidial masses off leaves with abundant sporulation using a stainless-steel spatula, which was thoroughly cleaned and flame sterilized between isolates.

Two or three glass beads $(2 \mathrm{~mm})$ were added to the spore pellet and the tube was placed in liquid nitrogen for quick freezing. Then, the spore pellet was bead-beaten using a mini-beadbeater-1 (BioSpec Products, Inc.) for $30 \mathrm{~s}$ at 2,500 rpm, placed back in liquid nitrogen, and this step was repeated three times. After the bead beating, $300 \mu \mathrm{l}$ of RLT buffer (provided in the Qiagen Biosprint DNA Plant Kit) was added for the lysis of cells and the tube was mixed vigorously using a Deluxe Vortex Mixer (Fisher Scientific). The tube was centrifuged for $5 \mathrm{~min}$ at $3,340 \times \mathrm{g}$. The DNA in the lysate was purified using the Qiagen BioSprint 15 platform following manufacturer's protocol (Qiagen). The DNA extract was transferred into a fresh, sterile centrifuge tube and stored in the freezer $\left(-80^{\circ} \mathrm{C}\right)$ until use.

SYBR Green quantitative PCR was used to determine the presence and to quantify the percentage of the G143A mutation in the $c y t b$ gene. The primer sequences used to detect the mutation in the E. necator and P. viticola mildew isolates were (Baudoin et al. 2008; Sirven and Beffa 2003), for downy mildew, mutant allele (resistant): 5'-GGACAAATGAGTTTTTGGGC-3', wild-type allele: 5'-GGACAAATGAGTTTTTGGGG-3', and common reverse: 5'ATTATCAACGGCGAATCCAC-3'; and, for powdery mildew, mutant allele (resistant): 5'-TACGGGCAGATGAGCCTATGCGC-3', wildtype allele: 5'-TACGGGCAGATGAGCCTATGCGG -3', and common reverse: 5'-ACCTACTTAAAGCTTTAGAAGTTTCC-3'.

The components of each PCR were $5 \mu$ l of DNA extract (between $1 \times 10^{-3}$ and $\left.1 \times 10^{-6} \mathrm{ng} / \mu \mathrm{l}\right), 2.5 \mu \mathrm{l}$ each of forward and reverse primer ( $5 \mu \mathrm{M}$ stock), $2.5 \mu \mathrm{l}$ of sterile distilled water, and $12.5 \mu \mathrm{l}$ of Bio-Rad $2 \times$ iQ SYBR Green Supermix containing SYBR green, nucleotides, and enzyme.

The real-time reaction parameters were based on Sirven and Beffa (2003) with the following modifications: $95^{\circ} \mathrm{C}$ for $4 \mathrm{~min}$ and $40 \mathrm{cy}$ cles of $95^{\circ} \mathrm{C}$ for $10 \mathrm{~s}, 58^{\circ} \mathrm{C}$ for $15 \mathrm{~s}$, and $72^{\circ} \mathrm{C}$ for $15 \mathrm{~s}$. Data were collected during the $72^{\circ} \mathrm{C}$ step.

The $\% \mathrm{G} 143 \mathrm{~A}$ of each isolate was calculated using the formula:

$$
\begin{aligned}
\% \mathrm{G} 143 \mathrm{~A}= & {\left[1 /\left[2^{(\text {Mutant Ct}- \text { Wild type Ct })}+1\right]\right] } \\
& \times 100 \%(\text { Sirven and Beffa } 2003)
\end{aligned}
$$

\section{Results}

Reproducibility of the powdery mildew bioassay tests. The reproducibility of the powdery mildew bioassay tests for azoxystrobin, boscalid, and quinoxyfen was determined by testing nine sensitive isolates four to five times, as described previously (Colcol et al. 2012). The $\mathrm{EC}_{50}$ values of the repeated tests for azoxystrobin, boscalid, and quinoxyfen showed moderate variation; coefficients of variation averaged $32 \%$ and ranged from 14 to $66 \%$ (Table 1), which is similar to values computed by Wong and Wilcox (2002) for azoxystrobin (mean $31 \%$, range 10 to $66 \%$ ).

Powdery mildew sensitivity to azoxystrobin. In our bioassays, the mean and median $\mathrm{EC}_{50}$ values for azoxystrobin of our E. necatorsensitive subgroup ( $n=9$; Table 1$)$ were very similar to $\mathrm{EC}_{50}$ values of sensitive E. necator isolates collected from New York in 1999 (Wong and Wilcox 2002). 
The frequency distribution of the $\log -\mathrm{EC}_{50}$ values of $154 \mathrm{E}$. necator isolates from QoI-treated vineyards (exposed collection) was broad and continuous, ranging from $\log _{10}$ values of -2.5 to 2.0 , but bimodal (Fig. 1). We categorized isolates with $\mathrm{EC}_{50}<1 \mu \mathrm{g} / \mathrm{ml}$ as sensitive and $\geq 1 \mu \mathrm{g} / \mathrm{ml}$ as resistant, the same criterion used previously (Baudoin et al. 2008). Of the 154 E. necator isolates, 28 $(18 \%)$ were QoI sensitive and 126 isolates $(82 \%)$ were QoI resistant. $\mathrm{EC}_{50}$ values of 1 to $10 \mu \mathrm{g} / \mathrm{ml}$ were designated as intermediate resistance while $\mathrm{EC}_{50}$ values greater than $10 \mu \mathrm{g} / \mathrm{ml}$ were designated as high resistance. In all, $79(63 \%)$ of the QoI-resistant isolates were highly resistant and 47 isolates $(37 \%)$ had intermediate resistance (Fig. 1). Resistant isolates were collected from all geographic areas sampled throughout Virginia and nearby areas of North Carolina, Maryland, and Pennsylvania, the same or similar locations as reported previously (Baudoin et al. 2008; Colcol et al. 2012), indicating that QoI resistance is widespread in this region.

There was a significant shift in the median $\mathrm{EC}_{50}$ for azoxystrobin of isolates of $E$. necator from exposed vineyards compared with the sensitive subgroup (Fig. 1). Exposed isolates had a median $\mathrm{EC}_{50}$ of $10.8 \mu \mathrm{g} / \mathrm{ml}\left(\log \mathrm{EC}_{50}\right.$ range from -2.5 to 2.0$)$ compared with a median $\mathrm{EC}_{50}$ of $0.007 \mu \mathrm{g} / \mathrm{ml}\left(\log \mathrm{EC}_{50}\right.$ range from -2.5 to -1.5 ) for the sensitive subgroup (Table 1; Fig. 1). The magnitude of the shift of the median $\mathrm{EC}_{50}$ of exposed E. necator isolates was 1,526-fold (3.2 log units). Because the frequency distributions were somewhat skewed and, therefore, not log normally distributed, the nonparametric Wilcoxon/Kruskal Wallis test was performed to determine whether the distribution of the exposed collection differed from that of the E. necator subgroup sensitive to azoxystrobin. The difference was highly significant $(P<0.0001)$.

Based on the SYBR-green real-time PCR results, all the E. necator isolates in the sensitive subgroup had G143A $<1 \%$. Of the exposed E. necator isolates, $73 \%(n=112)$ had G143A $>1 \%$ (usually $>99 \%$ ) and had a broad range of $\mathrm{EC}_{50}$ values ranging from $1 \mu \mathrm{g} / \mathrm{ml}$ to greater than $10 \mu \mathrm{g} / \mathrm{ml}$ (Fig. 1). The remaining 27\% $(n=42)$ of E. necator isolates had $\mathrm{G} 143 \mathrm{~A}<1 \%$. In all, 28 of the 42 isolates had $\mathrm{EC}_{50}$ values less than $1 \mu \mathrm{g} / \mathrm{ml}$ and the remaining 14 had $\mathrm{EC}_{50}$ values above $1 \mu \mathrm{g} / \mathrm{ml}$ (classified as QoI resistant based on our criterion).

Downy mildew sensitivity to azoxystrobin. A large majority $(92 \%)$ of the 153 P. viticola isolates tested against azoxystrobin at 1 and $10 \mu \mathrm{g} / \mathrm{ml}$ were resistant (they grew at concentrations $>1 \mu \mathrm{g} / \mathrm{ml})$. QoI resistance was found in all regions sampled in this study. The $\mathrm{EC}_{50}$ of the resistant $P$. viticola isolates was difficult to determine accurately because, when the leaf discs used for the bioassay were soaked in a higher dose of azoxystrobin, they died due to phytotoxicity, a phenomenon previously reported for azoxystrobin (Baudoin et al. 2008) and by Wong and Wilcox (2000) for kresoximmethyl and trifloxystrobin.

When results of the bioassay and real-time PCR were combined, the isolates fell into three groups: $92 \%$ of isolates were QoI resistant, with the $c y t b$ G143A mutation frequency $>1 \%$ (usually $>95 \%$ ); $7.6 \%$ were QoI-sensitive, with $\mathrm{G} 143 \mathrm{~A}<1 \%$; and the one remaining isolate was QoI-resistant, with G143A $<1 \%$.

Spray records for the 2 to 5 years before sample collection were obtained for 19 of 28 sites from which downy mildew was collected, representing 119 of 153 isolates and 20 of 31 powdery mildew sites (132 of 163 isolates). QoI fungicides had been applied an average of
2.6 times per year at 16 of 19 downy mildew sites (range 1.3 to 4.7 ) and 2.9 times per year at 16 powdery mildew sites (range 0.5 to 4.8$)$.

Downy mildew sensitivity to mefenoxam. Bioassays with 153 $P$. viticola isolates from 26 vineyards in Virginia, Maryland, North Carolina, and Pennsylvania provided no evidence of any mefenoxam resistance. None of the isolates grew on leaf discs treated with $10 \mu \mathrm{g} / \mathrm{ml}$. Some $P$. viticola growth would commonly develop on discs treated with $1 \mu \mathrm{g} / \mathrm{ml}$; apparently, the effects of mefenoxam absorbed by soaking of leaf discs dissipated after lengthy incubation because, when leaf discs were floated on mefenoxam suspensions of $1 \mu \mathrm{g} / \mathrm{ml}$, these isolates did not grow. In contrast, metalaxyl-resistant $P$. viticola isolates from France (Gisi and Cohen 1996; Leroux and Clerjeau 1985) and Australia (Wicks et al. 2005) had $100 \%$ leaf disc sporulation at a metalaxyl concentration of $10 \mu \mathrm{g} / \mathrm{ml}$.

Spray records for the 2 to 5 years before sample collection were obtained for 19 of 28 sites from which downy mildew were collected, representing 119 of 153 isolates. Mefenoxam was used at 11 sites, representing 60 isolates, an average of 0.7 times per year (range 0.2 to 1.5$)$.

Powdery mildew sensitivity to boscalid. To date, all E. necator isolates $(n=160)$ tested against boscalid have been sensitive; they did not grow on leaf tissue treated with a concentration of $0.3 \mu \mathrm{g} / \mathrm{ml}$. In order to provide a baseline for comparison with isolates collected in the future, the QoI-sensitive (above) and DMI-sensitive (Colcol et al. 2012) E. necator subgroup $(n=9)$ that has been used for comparison was tested repeatedly against boscalid, and the range and mean of their $\mathrm{EC}_{50}$ are shown in Table 1. The calculated range and mean of the $\mathrm{EC}_{50}$ of the boscalid-sensitive E. necator isolates was lower than the mean and range of $\mathrm{EC}_{50}$ of sensitive isolates from California, which were 0.0039 to $0.052 \mathrm{mg} / \mathrm{liter}$ (mean = $0.022 \mu \mathrm{g} / \mathrm{ml}$ ) (Wong et al. 2003).

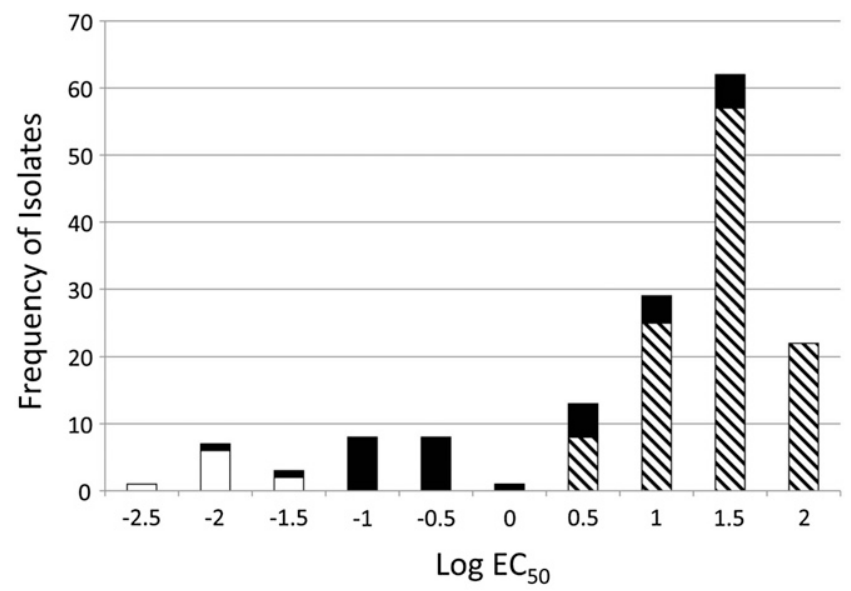

Fig. 1. Frequency distribution of the $\log _{10} 50 \%$ effective concentration $\left(E C_{50}\right)$ of Erysiphe necator to azoxystrobin. White portions of bars represent the azoxystrobin-sensitive subgroup $(n=9)$, black as well as white portions of bars represent isolates with $\mathrm{G} 143 \mathrm{~A}<1 \%(n=42)$, and diagonally striped portions of bars represent isolates with $\mathrm{G} 143 \mathrm{~A}>1 \%$ mutation $(n=112)$.

Table 1. Values for $50 \%$ effective concentration of the sensitive subgroup $(n=9)$ and of our exposed $(n=154)$ Erysiphe necator collection from Virginia and nearby states to azoxystrobin, boscalid, and quinoxyfen

\begin{tabular}{|c|c|c|c|c|c|c|}
\hline \multirow[b]{2}{*}{ Fungicide } & \multicolumn{4}{|c|}{ Sensitive subgroup ( $\mu \mathrm{g}$ a.i. $/ \mathrm{ml}$ ) } & \multicolumn{2}{|c|}{ Exposed collection ( $\mu \mathrm{g}$ a.i. $/ \mathrm{ml})$} \\
\hline & Mean & Median & Range & $\mathrm{CV}(\%)^{\mathrm{a}}$ & Median & $\overline{\text { Mean }}$ \\
\hline Azoxystrobin & 0.017 & 0.007 & $0.003-0.050$ & $32(14$ to 62$)$ & 10.8 & 13.0 \\
\hline Quinoxyfen & 0.018 & 0.013 & $0.006-0.066$ & $29(14$ to 62$)$ & $<0.3$ & $<0.3$ \\
\hline Boscalid & 0.009 & 0.005 & $0.0005-0.025$ & $37(14$ to 66$)$ & $<0.3$ & $<0.3$ \\
\hline
\end{tabular}

${ }^{a}$ Coefficients of variation. 
We have continued monitoring by placing potted grape plants near vineyards during the 2008 to 2012 growing seasons and spraying them on a weekly basis for approximately 3 months with low (discriminatory) rates of boscalid, quinoxyfen, and several other fungicides in order to detect potentially rare resistant isolates; control plants were sprayed with water. We collected meaningful data from eight sites, some for several years. Although some powdery mildew development occasionally occurred on the treated plants, none of the isolates recovered had any boscalid resistance nor did any isolates recovered before 2013 have any unusual quinoxyfen response. This approach can be used to continue monitoring of the E. necator population to detect any resistance development early.

Powdery mildew sensitivity to quinoxyfen. Prior to 2013, all E. necator isolates $(n=160)$ tested against quinoxyfen were sensitive; they had strongly reduced or no growth on leaf tissue treated with concentrations of 0.3 or $3 \mu \mathrm{g} / \mathrm{ml}$. The $\mathrm{EC}_{50}$ range of the nine isolates of the previously described sensitive subgroup is shown in Table 1.

In September 2013, we collected E. necator isolates in a commercial vineyard in western Virginia where the grower had used quinoxyfen as a major component of the E. necator management program in certain blocks and reported difficulties with E. necator control in 2013. When this powdery mildew (hereafter referred to as Quintecresistant $[\mathrm{QR}]$ ) was inoculated onto leaves treated with quinoxyfen at rates up to $100 \mu \mathrm{g} / \mathrm{ml}$, growth was obtained at all rates, although spore germination was inhibited to various degrees compared with nontreated leaves (Table 2). When untreated leaves were omitted from the analysis, the dose effect of quinoxyfen concentration on spore germination was not significant in any experiment (Table 2). Germ tube length was usually little or not affected by quinoxyfen treatment (Table 2; Fig. 2). Numbers of colonies and of conidia produced on treated leaves were 30 to $80 \%$ of those on control leaves, with little apparent dose response, making it difficult to estimate an $\mathrm{EC}_{50}$ value. In two experiments, E. necator development on leaf tissue treated by soaking for $1 \mathrm{~h}$ followed by contact with impregnated filter paper for $24 \mathrm{~h}$ was inhibited somewhat more than on tissue treated by soaking alone $(P<0.05)$ but there was no difference in a third experiment (data not shown).

Small potted Chardonnay grape plants were sprayed with quinoxyfen at 25,50 , and $100 \mu \mathrm{g} / \mathrm{ml}$ and inoculated by dusting QR spores over them the next day. Twelve days after inoculation, average powdery mildew coverage (percentage of surface) of leaves that had not yet completely lost their shine at the time of inoculation was $20 \%$ for plants not treated and 14,10 , and $18 \%$ for plants treated with quinoxyfen at 25,50 , and $100 \mu \mathrm{g} / \mathrm{ml}$, respectively (one plant per treatment, 7 to 12 rated leaves per plant). A plant treated with quinoxyfen at $10 \mu \mathrm{g} / \mathrm{ml}$ and inoculated with a sensitive isolate remained mildew free. Additional plants treated with 50 or $75 \mu \mathrm{g} / \mathrm{ml}$ and inoculated with QR also became heavily infected.

Spray records for the 2 to 5 years before sample collection of the 2005 to 2008 isolates were obtained for 20 of 31 powdery mildew sites (132 of 163 isolates). Boscalid, usually in the form of Pristine (BASF Corporation), was applied to 10 powdery mildew sites at an average 1.7 times per year (range 0.2 to 3.7 ), and quinoxyfen to 4 sites at an average 1.4 times yearly (range 0.7 to 2.5 times). The

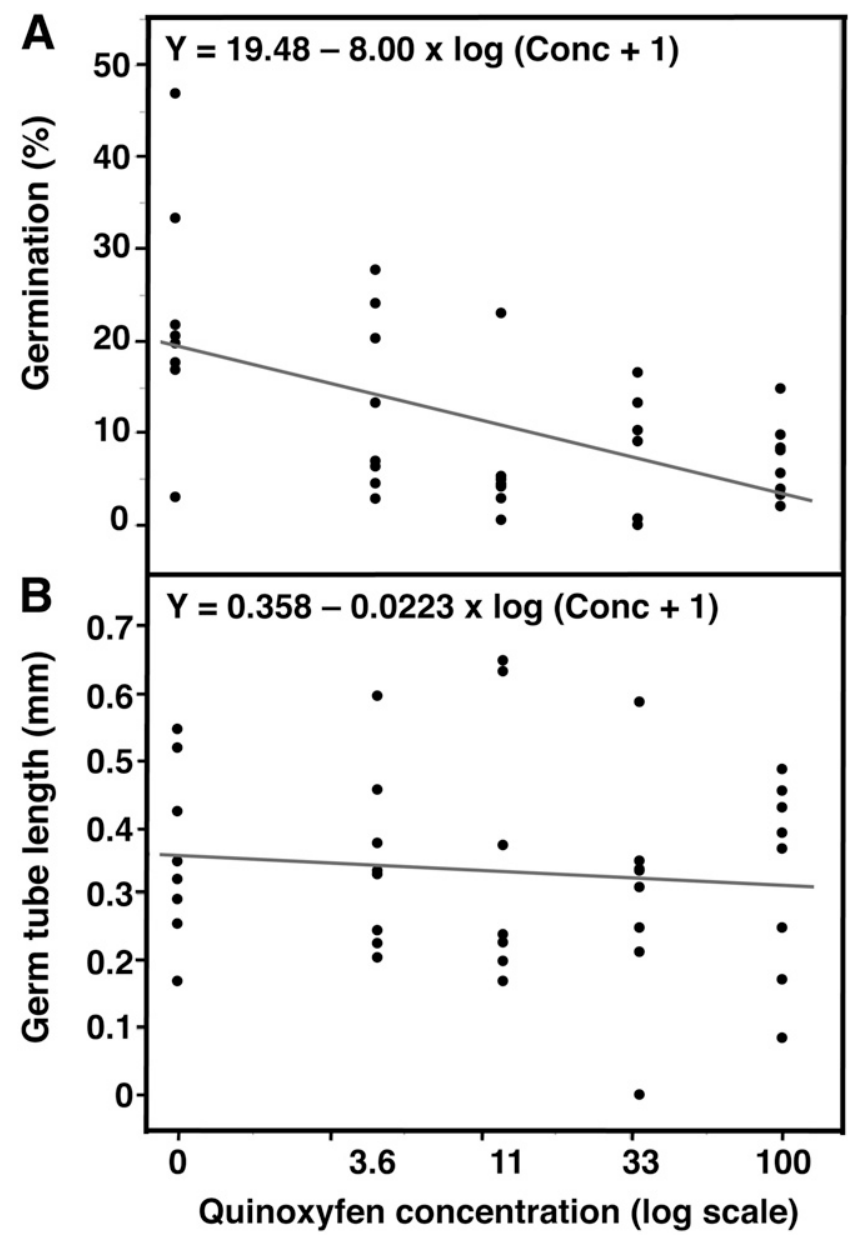

Fig. 2. A, Percent germination and B, germ tube length of quinoxyfen-resistant Erysiphe necator on treated grape leaf pieces (experiment 3 ).

Table 2. Germination, germ tube length, number of colonies, surface coverage, and conidial production by quinoxyfen-resistant Erysiphe necator in response to various quinoxyfen concentrations

\begin{tabular}{|c|c|c|c|c|c|c|c|c|c|c|c|}
\hline \multirow[b]{2}{*}{ Experiment, feature } & \multicolumn{9}{|c|}{ Quinoxyfen concentration } & \multirow[b]{2}{*}{$P(\mathrm{wCon})^{\mathrm{a}}$} & \multirow[b]{2}{*}{$P(\text { woCon })^{\mathrm{a}}$} \\
\hline & $\mathbf{0}$ & 1.5 & 3.6 & 5 & 11 & 15 & 33 & 50 & 100 & & \\
\hline \multicolumn{12}{|l|}{ Experiment 1} \\
\hline Germination (\%) & 40.4 & 15.4 & $\ldots$ & 38.6 & $\ldots$ & 17.5 & $\ldots$ & 20.1 & $\ldots$ & 0.09 & 0.814 \\
\hline Germ tube length & 62.1 & 26.4 & $\ldots$ & 38.6 & $\ldots$ & 38 & $\ldots$ & 30.4 & $\ldots$ & 0.031 & 0.785 \\
\hline Colonies & 26.3 & 21.9 & $\ldots$ & 17.2 & $\ldots$ & 27.1 & $\ldots$ & 18.5 & $\ldots$ & 0.484 & 0.593 \\
\hline Coverage $(\%)$ & 86.1 & 59 & $\ldots$ & 53 & $\ldots$ & 49.8 & $\ldots$ & 39.6 & $\ldots$ & $<0.0001$ & 0.011 \\
\hline \multicolumn{12}{|l|}{ Experiment 2} \\
\hline Germination (\%) & 18.3 & $\ldots$ & 6.2 & $\ldots$ & 5.8 & $\ldots$ & 9 & $\ldots$ & 1.1 & 0.693 & 0.284 \\
\hline Germ tube length & 24.2 & $\ldots$ & 26.4 & $\ldots$ & 32.3 & $\ldots$ & 20.7 & $\ldots$ & 42 & 0.901 & 0.78 \\
\hline Colonies & 12.2 & $\ldots$ & 5.8 & $\ldots$ & 3.9 & $\ldots$ & 7.1 & $\ldots$ & 6.2 & 0.15 & 0.252 \\
\hline Conidia & 94 & $\ldots$ & 52.6 & $\ldots$ & 26.3 & $\ldots$ & 45.1 & $\ldots$ & 29.6 & 0.062 & 0.454 \\
\hline \multicolumn{12}{|l|}{ Experiment 3} \\
\hline Germination (\%) & 32.7 & $\ldots$ & 16.6 & $\ldots$ & 7.2 & $\ldots$ & 9.2 & $\ldots$ & 7.7 & 0.003 & 0.076 \\
\hline Germ tube length & 36.4 & $\ldots$ & 34.7 & $\ldots$ & 33.7 & $\ldots$ & 29.6 & $\ldots$ & 33 & 0.681 & 0.666 \\
\hline Colonies & 22 & $\ldots$ & 14.1 & $\ldots$ & 13.8 & $\ldots$ & 16.3 & $\ldots$ & 19.8 & 0.557 & 0.884 \\
\hline
\end{tabular}

a $P=$ probability that slope differs from zero. $P$ (wCon) included the control in the analysis and $P$ (woCon) considers only the nonzero rates of quinoxyfen. 
vineyard blocks where the resistant population was found in fall 2013 had been exposed to quinoxyfen applications since 2006: two applications in 2006, 2007, and 2010; one in 2008; three in 2009; and four in 2011, 2012, and 2013. The majority of these had been mixed with low rates ( 1 to $3 \mathrm{lbs}$./acre or 1.1 to $3.4 \mathrm{~kg} / \mathrm{ha}$ ) of sulfur or label rates of another antipowdery mildew fungicide.

Powdery mildew sensitivity to benzimidazoles. Data on thiophanate methyl (Topsin M 70WP) sensitivity were obtained for 84 isolates from 29 locations, although tests for only 27 of these, representing 20 locations, were repeated two to five times. Most of the isolates grew well on leaf tissue treated with formulated Topsin $\mathrm{M}$ at 50 and $250 \mu \mathrm{g}$ a.i./ml, although growth of several isolates from a few locations was inconsistent. The labeled rate is 0.75 to $1.5 \mathrm{lbs} . / \mathrm{acre}$ at 14- to 21-day intervals; for a spray volume of 100 gal./acre or 935 liter/ha, this would translate into 630 to $1,260 \mu \mathrm{g}$ a.i./ml. Because resistance appeared to be unexpectedly widespread, the response of several isolates was confirmed by testing against a different batch of Topsin M, a different formulation of thiophanate methyl (Cleary 3336 Plus; Cleary Chemical Corp.), and benomyl (Benlate 50DF; E.I. du Pont de Nemours). Results with Cleary 3336 Plus were similar to those with Topsin M but several isolates were more strongly inhibited by Benlate than by Topsin $\mathrm{M}$. There were at least two different levels of resistance: isolates inhibited by benomyl at $250 \mu \mathrm{g}$ a.i. $/ \mathrm{ml}$ but not at $50 \mu \mathrm{g} / \mathrm{ml}$, and isolates inhibited by neither. Results with benomyl are of no practical relevance because benomyl is no longer registered.

Potted grape plants were placed outdoors during the summers of 2010 and 2011 and sprayed with Topsin M every 7 days for over 3 months. Control plants were sprayed with water. At two commercial vineyards, plants treated weekly with $200 \mu \mathrm{g}$ a.i./ml developed just as much powdery mildew as the control plants but, at the third location, which was not near any vineyard and where powdery mildew isolates had been found sensitive to other fungicides, plants treated with $100 \mu \mathrm{g}$ a.i./ml remained mildew free for most of the two seasons; only one plant developed a limited amount of E. necator colonization at the end of the second season, suggesting a low frequency of thiophanate methyl resistance. Among the 20 powdery mildew sites for which spray records were obtained, only 2 had had Topsin M applied (one and two applications, respectively) in 1 year only. Grape powdery mildew resistance to thiophanate methyl appears to be widespread; therefore, this fungicide is not recommended as a useful alternative.

\section{Discussion}

QoI resistance of both grape powdery and downy mildew in Virginia in 2005 to 2008 was so prevalent and widespread as to render use of these compounds inadvisable for control of these two diseases. Occasional samples received from growers in the years since the initial survey indicate that this situation persists.

The discriminatory dose of azoxystrobin that we used for both pathogens $(1 \mu \mathrm{g} / \mathrm{ml})$ differs slightly from those used by Wong and Wilcox; namely, $0.5 \mu \mathrm{g} / \mathrm{ml}$ for $P$. viticola (Wong and Wilcox 2000 ) and $2 \mu \mathrm{g} / \mathrm{ml}$ for E. necator (Wong and Wilcox 2002). The median $\mathrm{EC}_{50}$ of our $E$. necator QoI-sensitive subgroup was $0.007 \mu \mathrm{g} / \mathrm{ml}$, and only $2 \%$ of isolates would have been classified differently with a $2-\mu \mathrm{g} / \mathrm{ml}$ cutoff.

In both pathogens, the QoI resistance was most commonly due to the G143A mutation, and the real-time PCR method can be used to quickly screen samples for QoI resistance. However, 14 of 154 QoIresistant powdery mildew isolates and 1 of 153 resistant downy mildew isolates had G143A <1\%; therefore, isolates that lack G143A should still be tested by conventional bioassay to detect isolates with QoI resistance due to a different mechanism. Resistance of such isolates may be conferred by other mutations such as F129 L, which has been reported for P. viticola (Sierotzki et al. 2005), or G137R (Ma and Michailides 2005; Sierotzki et al. 2007), or other mechanisms that were not explored in this study. Alternatively, the proportion of G143A-mutated mitochondria may have been below the detectable level, a phenomenon reported for QoI-resistant isolates of Podosphaera leucotricha (Lesemann et al. 2006) and Botrytis cinerea (Ishii et al. 2009). Of these 14 isolates, 7 came from a single vineyard that is thought to have had a QoI-resistant population in 2002, based on frequent QoI use in prior years and powdery mildew control failure in 2002, and where QoI fungicides had not been used for the 5 years from 2002 until the time of sample collection in 2007. Of the 20 isolates collected from this location, 3 had G143A $>99 \%$ and were QoI resistant in bioassay; 3 were QoI sensitive, with G1143A $<1 \%$; and the remainder gave borderline readings or were tested only by bioassay or PCR before being lost. This appears consistent with a hypothesis of the low-G143A isolates being a residual of a resistant population. The remaining resistant isolates with low G143A came from locations where they made up only a small fraction of the population. Sequencing of the cyt $b$ gene of E. necator isolates that were resistant to QoI but contained $<1 \%$ G143A might help determine whether mutations other than G143A were present but sequencing of this part of the gene has proven to be difficult (Rallos 2012).

Because the majority of our QoI-resistant Plasmopara viticola and E. necator isolates tested possessed G143A, we expect that these isolates are also resistant to additional QoI fungicides such as pyraclostrobin, trifloxystrobin, and others. We have only confirmed this with a limited number of isolates but have found no exceptions. A strong QoI cross-resistance has often been detected in pathogens that have been tested (Chin et al. 2001; Ishii et al. 2001; Kim et al. 2003), although there were indications of somewhat different intrinsic activities among QoI (Wong and Wilcox 2000). Kim et al. (2003) reported that, for Pyricularia grisea, the G143A mutation conferred cross-resistance between the QoI but the F129 L mutation did not.

Metalaxyl or mefenoxam resistance was not found in our samples, indicating, at a minimum, that it is uncommon in Virginia and, to date, has not been reported for Plasmopara viticola in North America. Resistance management practices that limit this compound to four applications per season, and only in mixtures with copper or mancozeb, have apparently been effective. In addition, mefenoxam is relatively expensive, which discourages overuse. Because mefenoxam has a high risk of resistance development (Gisi and Cohen 1996), it should be monitored in order to detect resistance early. It would be helpful to focus sampling in vineyards with relatively intensive use of mefenoxam but this depends on growers volunteering information on their fungicide application practices before they perceive that a likely problem exists; we found it difficult to obtain this information.

The FRAC has classified quinoxyfen as at medium risk, boscalid at medium to high risk, and azoxystrobin at high risk of resistance development (FRAC 2015). Boscalid and quinoxyfen became registered for use on U.S. grape cultivars in 2003, and the time available for resistance to develop before our 2006 and 2007 sampling had been limited. Because E. necator resistance to the QoI is now widespread and many E. necator isolates also had lower sensitivity to the DMI (Colcol et al. 2012), growers may have increased their use of boscalid and quinoxyfen. To date, no boscalid-resistant E. necator isolates have been reported anywhere. However, boscalid resistance has been detected in several other pathogens, including A. alternata (Avenot et al. 2008), D. bryoniae (Avenot et al. 2012), C. cassiicola (Miyamoto et al. 2009), B. cinerea (FRAC 2013), and Podosphaera xanthii (McGrath and Miazzi 2008; Miyamoto et al. 2010), with the resistant isolates having high resistance factors.

Quinoxyfen-resistant isolates of Blumeria graminis f. sp. hordei have been generated in the laboratory as well as collected in the field (Genet and Jaworska 2009; Hollomon et al. 1997) and are sometimes associated with a reduction of quinoxyfen's field efficacy (Genet and Jaworska 2009). The $\mathrm{EC}_{50}$ of these resistant isolates was unclear but they grew at $160 \mu \mathrm{g} / \mathrm{ml}$. These quinoxyfen-resistant isolates were defective and were able to survive only in the presence of quinoxyfen, and such isolates would probably not have been detected by our procedures prior to 2013, where most isolates were cultured repeatedly on untreated leaf tissue prior to bioassay. Our QR E. necator isolates did not appear morphologically abnormal, and several have been maintained for over a year by repeated transfer on both treated and untreated leaves.

In a study of baseline sensitivity of $E$. necator with 56 unexposed isolates, Green and Duriatti (2005) and Green and Gustafson (2006) reported an $\mathrm{EC}_{50}$ range of 0.03 to $2.6 \mu \mathrm{g} / \mathrm{ml}$, which was higher and 
wider than the 0.006 to $0.066 \mu \mathrm{g} / \mathrm{ml}$ of the smaller set of nine isolates in our unexposed subgroup. Part of this may have been due to a difference in technique; in our earlier tests, we exposed leaf tissue by soaking for $1 \mathrm{~h}$ in fungicide suspensions whereas Green and Gustafson (2006) exposed leaf tissue to quinoxyfen-impregnated paper for $24 \mathrm{~h}$. In our comparisons of a 1-h soak only with a 1-h soak followed by $24-h$ contact with quinoxyfen-impregnated paper, prolonged contact increased inhibition in two of three trials. Some E. necator isolates in Green and Gustafson's (2006) baseline population were capable of limited growth on leaves treated with high rates of quinoxyfen, and selected $E$. necator isolates with $\mathrm{EC}_{50}$ values considerably higher than $2.6 \mu \mathrm{g} / \mathrm{ml}$ have been detected in the field (Genet and Jaworska 2009; Green and Gustafson 2006); however, other than the statements published by FRAC (2014), we have been unable to find information on their frequency, effect on disease control, or persistence.

Information on the resistance frequency, geographic extent, and persistence of quinoxyfen resistance and of possible residual efficacy of quinoxyfen for powdery mildew management in Virginia is still very limited; preliminary results obtained in 2014 indicate that these isolates are not widespread but additional survey and field trials will be needed to clarify these aspects. Label rates of quinoxyfen for grape range from 3 to 6.6 fluid oz./acre (approximately 60 to $130 \mu \mathrm{g}$ a.i. $/ \mathrm{ml}$ ) if 100 gal./acre (935 liters/ha) are applied; therefore, the degree of resistance exhibited in our leaf and potted-plant experiments appears more than sufficient to compromise quinoxyfen efficacy in the field. We conducted a replicated field trial in 2014 at the affected vineyard (data not shown), which was not completely successful because part of the trial was mistakenly sprayed with an antipowdery mildew fungicide in the middle of the season. However, the results obtained suggested that quinoxyfen may still have been effective at providing powdery mildew control, a claim also made on the FRAC website (FRAC 2014). The field trial will need to be repeated. Poor control of E. necator by quinoxyfen in field trials in western New York in 2010 and 2011 has been attributed to possible resistance but resistance was "hypothesized but not confirmed" (Wilcox and Riegel 2012a,b,c). Cucurbit powdery mildew (P. xanthii) strains that tolerated quinoxyfen at 40 and $80 \mu \mathrm{g} / \mathrm{ml}$ have recently been reported from cucurbit fields in New York (McGrath 2013) but impact on field efficacy has not been shown.

In conclusion, QoI fungicides and benzimidazoles are no longer recommended for powdery mildew control in Virginia due to widespread resistance. Sterol demethylation inhibitors should be used with caution because significant levels of resistance are present in some $E$. necator populations and this varies from vineyard to vineyard (Colcol et al. 2012). We found no instances of boscalid resistance. Also, new active ingredients have been introduced in recent years (fluopyram, metrafenone, and cyflufenamid) and can be used in combinations (rotations or mixtures) with the still-effective fungicides mentioned, as well as sulfur and other multisite fungicides. For downy mildew control, resistance to QoI fungicides is widespread but no resistance to mefenoxam or metalaxyl was detected. Sparing use of mefenoxam in rotation with more recently registered fungicides such as the carboxylic acid amide (CAA) fungicides (mandipropamid and dimethomorph), fluopicolide, cyazofamid, cymoxanil, and zoxamide, as well as fungicides with multisite (copper, mancozeb, and captan) and unknown (phosphites) modes of action may be sustainable for many years.

\section{Acknowledgments}

We thank the Virginia Wine Board, Viticulture Consortium: East, the North Carolina Wine and Grape Council, and the Virginia Agricultural Council for their financial support; E. Bush, A. Woods-Jones, and C. Vasquez for assistance in optimizing the SYBR-green real-time PCR protocol; J. Lewis, Z. Miller, J. Kuen, Y. Chung, S. Sheffield, N. O'Malley, S. Park, A Qureshi, and R. Suyes for performing bioassays; and L. E. Rallos and B. Schnicker for their helpful reviews of this manuscript.

\section{Literature Cited}

Avenot, H., Morgan, D. P., and Michailides, T. J. 2008. Resistance to pyraclostrobin, boscalid, and multiple resistance to Pristine (pyraclostrobin + boscalid) fungicide in
Alternaria alternata causing Alternaria late blight of pistachios in California. Plant Pathol. 57:135-140.

Avenot, H. F., Thomas, A., Gitaitis, R. D., Langston, D. B., and Stevenson, K. L. 2012. Molecular characterization of boscalid- and penthiopyrad-resistant isolates of Didymella bryoniae and assessment of their sensitivity to fluopyram. Pest Manage. Sci. 68:645-651.

Bartlett, D. W., Clough, J. M., Godwin, J. R., Hall, A. A., Hamer, M., and Parr-Dobrzanski, B. 2002. The strobilurin fungicides. Pest Manage. Sci. 58:649-662.

Baudoin, A., Olaya, G., Delmotte, F., Colcol, J. F., and Sierotzki, H. 2008. QoI resistance of Plasmopara viticola and Erysiphe necator in the mid-Atlantic United States. Online publication. Plant Health Prog. doi:10.1094/PHP-2008-0211-02-RS

Blum, M., and Gisi, U. 2008. Inheritance of resistance in Plasmopara viticola Pages 101-104 in: Modern Fungicides and Antifungal Compounds V. H. W. Dehne, H. B. Deising, U. Gisi, K. H. Kuck, P. E. Russell, and H. Lyr, eds. Deutsche Phytomedizinische Gesellschaft, Braunschweig, Germany.

Brent, K. J., and Hollomon, D. W. 2007. Fungicide Resistance in Crop Pathogens: How Can It Be Managed? FRAC Monogr. No. 1, 2nd revised ed. Fungicide Resistance Action Committee, Croplife International, Brussels. Online publication. http://www.frac.info/docs/default-source/publications/monographs/monograph-2.pdf

Chen, W. J., Delmotte, F., Cervera, S. R., Douence, L., Greif, C., and Corio-Costet, M. F. 2007. At least two origins of fungicide resistance in grapevine downy mildew populations. Appl. Environ. Microbiol. 73:5162-5172.

Chin, K. M., Wirz, M., and Laird, D. 2001. Sensitivity of Mycosphaerella fijiensis from banana to trifloxystrobin. Plant Dis. 85:1264-1270.

Colcol, J. F. 2008. Fungicide Sensitivity of Erysiphe necator and Plasmopara viticola from Virginia and nearby states. M.S. thesis, Virginia Tech, Blacksburg.

Colcol, J. F., Rallos, L., and Baudoin, A. 2012. Sensitivity of Erysiphe necator to demethylation inhibitor fungicides in Virginia. Plant Dis. 96:111-116.

FRAC. 2012. QoI working group of FRAC, Minutes of the meeting, All crops Frankfurt, Germany December 5, 2012. Online publication. http://www.frac. info/docs/default-source/qoi-wg/qoi-meeting-minutes/minutes-of-the-2012qoi-meeting-recommendations-for-2013.pdf

FRAC. 2013. FRAC list of plant pathogenic organisms resistant to disease control agents Online publication. http://www.frac.info/docs/default-source/publications/listof-resistant-plant-pathogens/list-of-resistant-plant-pathogenic-organismsfebruary-2013.pdf

FRAC. 2014. Azanapthalene (AZN) Working Group, Annual Meeting March 10th, 2014. Protocol of the discussions and recommendations of the AZN Working Group of the Fungicide Resistance Action Committee (FRAC) Online publication. http://www.frac.info/docs/default-source/working-groups/aznfungicides/group/minutes-of-the-2014-azn-meeting-recommendations-for2015.pdf

FRAC. 2015. FRAC code List: Fungicides sorted by mode of action. Online publication http://www.frac.info/docs/default-source/publications/frac-code-list/frac-codelist-2015-finalC2AD7AA36764.pdf

Genet, J. L., and Jaworska, G. 2009. Baseline sensitivity to proquinazid in Blumeria graminis f. sp. tritici and Erysiphe necator and cross-resistance with other fungicides. Pest Manage. Sci. 65:878-884.

Genet, J.-L., Jaworska, G., and Deparis, F. 2006. Effect of dose rate and mixtures of fungicides on selection for QoI resistance in populations of Plasmopara viticola. Pest Manage. Sci. 62:188-194.

Gisi, U., Chin, K. M., Knapova, G., Farber, R. K., Mohr, U., Parisi, S., Sierotzki, H., and Steinfeld, U. 2000. Recent developments in elucidating modes of resistance to phenylamide, DMI and strobilurin fungicides. Crop Prot. 19:863-872.

Gisi, U., and Cohen, Y. 1996. Resistance to phenylamide fungicides: A case study with Phytophthora infestans involving mating type and race structure. Annu. Rev. Phytopathol. 34:549-572.

Gisi, U., and Sierotzki, H. 2008a. Fungicide modes of action and resistance in downy mildews. Eur. J. Plant Pathol. 122:157-167.

Gisi, U., and Sierotzki, H. 2008b. Molecular and genetic aspects of fungicide resistance in plant pathogens. Pages 53-61 in: Modern Fungicides and Antifungal Compounds V. H. W. Dehne, H. B. Deising, U. Gisi, K. H Kuck, P. E. Russell, and H. Lyr, eds. Deutsche Phytomedizinische Gesellschaft, Braunschweig, Germany

Gisi, U., Sierotzki, H., Cook, A., and McCaffery, A. 2002. Mechanisms influencing the evolution of resistance to Qo inhibitor fungicides. Pest Manage. Sci. 58:859-867.

Grasso, V., Palermo, S., Sierotzki, H., Garibaldi, A., and Gisi, U. 2006. Cytochrome $b$ gene structure and consequences for resistance to Qo inhibitor fungicides in plant pathogens. Pest Manage. Sci. 62:465-472.

Green, E., and Duriatti, A. 2005. Sensitivity of Uncinula necator isolates to quinoxyfen: Baseline studies, validation of baseline method, and targeted sensitivity monitoring after several years of commercial use. Pages 163-168 in: BCPC Int. Congr. Crop Sci. Technol. BCPC Publications Alton, Hampshire GU34 2QD, United Kingdom.

Green, E. A., and Gustafson, G. D. 2006. Sensitivity of Uncinula necator to quinoxyfen: Evaluation of isolates selected using a discriminatory dose screen. Pest Manage. Sci. 62:492-497.

Hollomon, D. W., Wheeler, I., Dixon, K., Longhurst, C., and Skylakakis, G. 1997. Defining the resistance risk of the new powdery mildew fungicide quinoxyfen. Pestic. Sci. 51:347-351.

Ishii, H., Fountaine, J., Chung, W. H., Kansako, M., Nishimura, K., Takahashi, K., and Oshima, M. 2009. Characterisation of Qol-resistant 
field isolates of Botrytis cinerea from citrus and strawberry. Pest Manage. Sci. 65:916-922.

Ishii, H., Fraaije, B. A., Sugiyama, T., Noguchi, K., Nishimura, K., Takeda, T., Amano, T., and Hollomon, D. W. 2001. Occurrence and molecular characterization of strobilurin resistance in cucumber powdery mildew and downy mildew. Phytopathology 91:1166-1171.

Kim, Y. S., Dixon, E. W., Vincelli, P., and Farman, M. L. 2003. Field resistance to strobilurin (QoI) fungicides in Pyricularia grisea caused by mutations in the mitochondrial cytochrome $b$ gene. Phytopathology 93:891-900.

Lee, S., Gustafson, G., Skamnioti, P., Baloch, R., and Gurr, S. 2008. Host perception and signal transduction studies in wild-type Blumeria graminis f. sp. hordei and a quinoxyfen-resistant mutant implicate quinoxyfen in the inhibition of serine esterase activity. Pest Manage. Sci. 64:544-555.

Leroux, P., and Clerjeau, M. 1985. Resistance of Botrytis cinerea Pers. and Plasmopara viticola (Berk. \& Curt.) Berl. and de Toni to fungicides in French vineyards. Crop Prot. 4:137-160.

Lesemann, S. S., Schimpke, S., Dunemann, F., and Deising, H. B. 2006. Mitochondrial heteroplasmy for the cytochrome $b$ gene controls the level of strobilurin resistance in the apple powdery mildew fungus Podosphaera leucotricha (Ell. \& Ev.) E. S. Salmon. J. Plant Dis. Prot. 113:259-266.

Ma, Z., and Michailides, T. J. 2005. Advances in understanding molecular mechanisms of fungicide resistance and molecular detection of resistant genotypes in phytopathogenic fungi. Crop Prot. 24:853-863.

McGrath, M. T. 2013. Efficacy of fungicides with resistance risk for cucurbit powdery mildew and fungicide sensitivity of Podosphaera xanthii in New York. (Abstr.) Phytopathology 103:S2.93.

McGrath, M. T., and Miazzi, M. M. 2008. Sensitivity of Podosphaera xanthii to registered fungicides at-risk for resistance related to their efficacy for powdery mildew in pumpkin. (Abstr.) Phytopathology 98:S102.

Miles, L. A., Miles, T. D., Kirk, W. W., and Schilder, A. M. C. 2012. Strobilurin (QoI) resistance in populations of Erysiphe necator on grapes in Michigan. Plant Dis. 96:1621-1628.

Miyamoto, T., Ishii, H., Seko, T., Kobori, S., and Tomita, Y. 2009. Occurrence of Corynespora cassiicola isolates resistant to boscalid on cucumber in Ibaraki Prefecture, Japan. Plant Pathol. 58:1144-1151.

Miyamoto, T., Ishii, H., and Tomita, Y. 2010. Occurrence of boscalid resistance in cucumber powdery mildew in Japan and molecular characterization of the ironsulfur protein of succinate dehydrogenase of the causal fungus. J. Gen. Plant Pathol. 76:261-267.

Pearson, R. C., and Taschenberg, E. F. 1980. Benomyl-resistant strains of Uncinula necator on grapes. Plant Dis. 64:677-680.

Rallos, L. E. E. 2012. Characterizing resistance of the grapevine powdery mildew Erysiphe necator to fungicides belonging to quinone outside inhibitors and demethylation inhibitors. Ph.D. dissertation, Virginia Tech, Blacksburg.

Reifschneider, F. J. B., and Boiteux, L. S. 1988. A vacuum-operated settling tower for inoculation of powdery mildew fungi. Phytopathology 78:1463-1465.

Sierotzki, H., Frey, R., Wullschleger, J., Palermo, S., Karlin, S., Godwin, J., and Gisi, U. 2007. Cytochrome b gene sequence and structure of Pyrenophora teres and P. tritici-repentis and implications for QoI resistance. Pest Manage. Sci. 63:225-233.
Sierotzki, H., Kraus, N., Assemat, P., Stanger, C., Cleere, S., Windass, J., and Gisi, U. 2005. Evolution of resistance to QoI fungicides in Plasmopara viticola populations in Europe. Pages 73-80 in: Modern Fungicides and Antifungal Compounds IV. H.-W. Dehne, U. Gisi, K. H. Kuck, P. E. Russell, and H. Lyr, eds. British Crop Protection Council, Alton, UK.

Sirven, C., and Beffa, R. 2003. Resistance to fenamidone: Monitoring by real time PCR on Plasmopara viticola. Pflanzenschutz-Nachr. Bayer 56: 523-532.

Stammler, G., Benzinger, G., and Speakman, J. 2007. A rapid and reliable method for monitoring the sensitivity of Sclerotinia sclerotiorum to boscalid. J. Phytopathol. 155:746-748.

Toffolatti, S. L., Serrati, L., Sierotzki, H., Gisi, U., and Vercesi, A. 2007. Assessment of QoI resistance in Plasmopara viticola oospores. Pest Manage. Sci. 63:194-201.

Wheeler, I. E., Hollomon, D. W., Gustafson, G., Mitchell, J. C., Longhurst, C. Zhang, Z., and Gurr, S. J. 2003. Quinoxyfen perturbs signal transduction in barley powdery mildew (Blumeria graminis f. sp. hordei). Mol. Plant Pathol. 4:177-186.

Wicks, T. J., Hall, B. H., and Somers, A. 2005. First report of metalaxyl resistance of grapevine downy mildew in Australia. Page 319 in: 15th Biennial Australas. Plant Pathol. Soc. Conf. Handb. Horticulture Australia, Sydney, Australia.

Wilcox, W. F., Burr, J. A., Riegel, D. G., and Wong, F. P. 2003. Practical resistance to QoI fungicides in New York populations of Uncinula necator associated with quantitative shifts in pathogen sensitivities. (Abstr.). Phytopathology 93:S90.

Wilcox, W. F., and Riegel, D. G. 2012a. Evaluation of fungicide programs for control of grapevine powdery mildew, 2010. Online publication. Plant Dis. Manage. Rep. 6:SMF048.pdf. http://www.plantmanagementnetwork.org/pub/ trial/pdmr/volume6/abstracts/smf048.asp

Wilcox, W. F., and Riegel, D. G. 2012b. Evaluation of fungicide programs for contro of grapevine powdery mildew on Chardonnay grapes, 2010. Online publication. Plant Dis. Manage. Rep. 6:SMF049.pdf. http://www.plantmanagementnetwork. $\mathrm{org} / \mathrm{pub} / \mathrm{trial} / \mathrm{pdmr} /$ volume6/abstracts/smf049.asp

Wilcox, W. F., and Riegel, D. G. 2012c. Evaluation of fungicide programs for control of grapevine powdery mildew, 2011. Online publication. Plant Dis. Manage. Rep. 6:SMF044. http://www.plantmanagementnetwork.org/pub/trial/ $\mathrm{pdmr} /$ volume6/abstracts/smf044.asp

Wong, F. P., and Wilcox, W. F. 2000. Distribution of baseline sensitivities to azoxystrobin among isolates of Plasmopara viticola. Plant Dis. 84:275-281.

Wong, F. P., and Wilcox, W. F. 2002. Sensitivity to azoxystrobin among isolates of Uncinula necator: Baseline distribution and relationship to myclobutanil sensitivity. Plant Dis. 86:394-404.

Wong, F. P., Wilcox, W. F., Burr, J. A., and Riegel, D. G. 2003. Baseline sensitivity distributions of Uncinula necator to boscalid and pyraclostrobin and field performance in New York. (Abstr.) Phytopathology 93:S91.

Ypema, H. L., Ypema, M., and Gubler, W. D. 1997. Sensitivity of Uncinula necator to benomyl, triadimefon, myclobutanil, and fenarimol in California. Plant Dis. 81:293-297. 